astronomer Torvald Køhl (Oversigt over det Kgl. Danske Vidensk. Selsk.'s Forh.), and it consists of 142 measurements of the lowest observed points of meteors (limes inferior). The material, obtained in latitude $56^{\circ} \mathrm{N}$. during the years $1875-1917$, is very accurate, the mean error of the heights being less than $1 \mathrm{~km}$.

The mean height of the limes inferior depends on the mass of air above this limit. Therefore, if the tides of the upper atmosphere have no phase-difference in relation to the tidal forces (which is nearly the case at ground level), the mean height of the lower limits may be expected to vary in the following manner :

$$
h=h_{0}+l \cos 2 t
$$

where $h_{0}$ is the mean height and $l$ the amplitude of a variation depending on the moon's hour-angle $(t)$. The material has been divided arbitrarily into two parts, and then each of these parts is divided in accordance with the moon's hour-angle, namely :

(1) flood-tide : $-30^{\circ}<t<30^{\circ}$ and $150^{\circ}<t<210^{\circ}$; (2) $+0: 30^{\circ}<t<45^{\circ}, 135^{\circ}<t<150^{\circ}, 210^{\circ}<$ $t<225^{\circ}$ and $315^{\circ}<t<330^{\circ}$;

(3) $-0 \quad: 45^{\circ}<t<60^{\circ}, 120^{\circ}<t<135^{\circ}, 225^{\circ}<$ $t<240^{\circ}$ and $300^{\circ}<t<315^{\circ}$;

(4) ebb-tide : $60^{\circ}<t<120^{\circ}$ and $240^{\circ}<t<300^{\circ}$.

The following table gives the mean values of $h$ in kilometres :

$\begin{array}{ccccc}\text { Years. } & \text { Flood-tide. } & +0 & -0 & \text { Ebb-tide. } \\ 1875-1902 & 87 \cdot 7 & 90 \cdot 6 & 81 \cdot 0 & 79 \cdot 9 \\ 1904-1917 & 92 \cdot 7 & 88 \cdot 6 & 78 \cdot 8 & 82 \cdot 8 \\ \text { hole period } & 89 \cdot 3 & 89 \cdot 4 & 79 \cdot 6 & 81 \cdot 6\end{array}$

From these values are found : $h_{0}=85 \cdot 0 \pm 1 \cdot 2 \mathrm{~km}$.; $l=5.5 \pm 1.9 \mathrm{~km}$., thus :

$$
h=85 \cdot 0+5 \cdot 5 \cos 2 t(\mathrm{~km} .) \text {. }
$$

Assuming from theory that, on an average, the meteors will be extinguished when they have passed through the same mass of air, the expression for $h$ shows that the mass of air situated above $90.5 \mathrm{~km}$. at flood-tide should be equal to the mass of air situated above $79.5 \mathrm{~km}$. at ebb-tide. The corresponding values formerly found by the investigation concerning the aurora were $106 \mathrm{~km}$. and $100 \mathrm{~km}$., respectively. Taking into consideration that the former phenomenon is observed in latitude $56^{\circ}$ and refers to heights about $85 \mathrm{~km}$. above the ground, while the latter phenomenon is observed in latitude $70^{\circ}$ and refers to heights about $103 \mathrm{~km}$., a fair agreement between the two results will be found.

A further examination of other and if possible more numerous observations of lower limits of the meteors would be of importance for the investigation of the tides of the upper atmosphere. J. EgEDAL.

Geofysisk Afdeling,

Meteorologisk Institut, Köbenhavn, Nov. 2.

\section{The Oxidation of Acetaldehyde by Oxygen.}

IN the course of experiments which have been carried out during the last two years on the photochemical oxidation of acetaldehyde, an observation has been made which does not seem to be recorded in the literature. It has been found that when pure liquid acetaldehyde is shaken at ordinary temperature with oxygen in daylight or in the dark, a rapid absorption of gas occurs and a peroxide is formed. 2 c.c. of liquid aldehyde, shaken for one minute with oxygen, absorb more than 1 c.c. of gas, and on adding the liquid to a solution of potassium iodide, iodine is liberated equivalent to about 8 c.c. of $n / 100$ thiosulphate solution.

The formation of peroxides under these conditions from other aldehydes has long been known, and Bäckström (Medd.K. Ventenskapsakad. Nobel-Inst. 6, No. 16) has recently investigated the chain mechanism of peroxide (benzoperacid) formation in the case of benzaldehyde. Bäckström assumed that the photochemical rate of peroxide formation is proportional to the light intensity. Mr. Chatwin, working in this laboratory, has shown that the rate of benzoperacid formation is more nearly proportional to the square root of the light intensity.

We have obtained similar results for acetperacid formation when gaseous acetaldehyde and oxygen are exposed to ultra-violet light. The reaction rate is high, indicating a long chain mechanism, and is approximately proportional to the square root of the light intensity, proportional to the aldehyde concentration, and independent of the oxygen concentration. These facts can only be explained by a mechanism of the following type :

$$
\begin{aligned}
& \text { 1. } \mathrm{A}+h \nu \rightarrow \mathrm{A}^{+} \\
& \text {2. } \mathrm{A}^{+}+\mathrm{O}_{2} \rightarrow \mathrm{AO}_{2}^{+} \\
& \text {3. } \mathrm{AO}_{2}^{+}+\mathrm{A} \rightarrow \mathrm{A}^{+}+\mathrm{AO}_{2} \\
& \text { 4. } 2 \mathrm{AO}_{2}^{+} \rightarrow \text { ? }
\end{aligned}
$$

That is to say, the chain mechanism given by reactions 2 and 3 must be assumed to be terminated by the reaction 4 to explain the observed kinetics. This otherwise improbable mechanism is rendered possible by the great length of the reaction chains.

We are now carrying out experiments on the oxidation of acetaldehyde in solutions, and full details of all the measurements will be published when further results are obtained.

$$
\text { E. J. BowEN. }
$$$$
\text { E. L. Tietz. }
$$

Physical Chemistry Laboratory,

Balliol and Trinity Colleges,

$$
\text { Oxford. }
$$

\section{New Phenomena in a Sounding Dust Tube.}

I HAvE found the clear photographs of the antinodal ring of dust in a Kundt's tube which were published in Nature on Nov. 9, p. 724, by Prof. Andrade and Mr. Lewer of special interest inasmuch as, while using a rod excited tube and Kieselsäure powder, I observed (Phil. Mag., vol. 7, p. 523, March 1929) an antinodal cloud and stated that "the antinodes are marked almost as definitely as the nodes". As the dust was photographed when the note had ceased, a photograph as detailed as that of Prof. Andrade and Mr. Lewer was not obtained, although a ring-like grouping at the antinode is clearly suggested in Fig. 7 (c') (l.c.).

I have observed that the striæ tend to lean over towards the nearest antinode and, in the photograph published in Nature, it may be seen that this tendency is marked to a minor degree. Also in my paper I pointed out that the figures depend largely on the powder used, and it would be of interest if, in their fuller account, Prof. Andrade and Mr. Lewer state the material they employed and the diameter of their tube.

Like Crofutt (J.O.S.A. and R.S.I., 14, p. 431, May 1927) I have used a valve oscillator to obtain striæ, and I was-before my experiments had to be temporarily suspended some months ago-photographing the figures kinematographically. The results of this investigation I hope to publish in due course. and, in the meantime, I look forward with interest to the contribution Prof. Andrade and Mr. Lewer have promised to make to this fascinating subject.

Department of Physics, ERIC J. Irons.

East London College, London, E.1, Nov. 19.

No. 3137 , VoL. 124] 